\title{
Sprayable Carbopol hydrogel with soluble beta-1,3/1,6-glucan as an active ingredient for wound healing - development and in-vivo evaluation
}

Jostein Grip $^{\mathrm{a}, \mathrm{b}}$, Rolf Einar Engstad ${ }^{\mathrm{a}}$, Ingrid Skjæveland ${ }^{\mathrm{a}}$, Nataša Škalko-Basnet ${ }^{\mathrm{b}}$, Ann Mari Holsæter $^{\text {b,* }}$

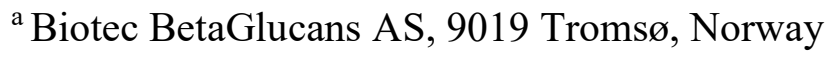

${ }^{\mathrm{b}}$ Drug Transport and Delivery Research Group, Department of Pharmacy, Faculty of Health Sciences, University of Tromsø The Arctic University of Norway, 9037 Tromsø, Norway

\section{*Corresponding author}

Ann Mari Holsæter

E-mail address: ann-mari.holsater@uit.no

Fax: (+47) 77644900

Telephone: (+47) 77646719

Drug Transport and Delivery Research Group, Department of Pharmacy, Faculty of Health Sciences, University of Tromsø The Arctic University of Norway, 9037 Tromsø, Norway 


\begin{abstract}
Chronic wounds represent a significant health problem worldwide. There is a need for advancedand cost-efficient wound healing products able to increase patient comfort and reduce the healing time. The aim of this study was to develop a sprayable hydrogel dressing with beta-glucan $(\beta G)$ as the active ingredient, targeting future application in the treatment of both chronic and burn wounds. The $\beta \mathrm{G}$ was chosen as an active ingredient because of its promising wound healing capabilities, whereas Carbopol 971P NF (Carbopol) was chosen as the thickening agent in the formulation due to several attractive characteristics such as its low viscosity, low toxicity, high transparency and good ion tolerance. Four different hydrogel formulations were prepared with varying Carbopol concentrations. The higher Carbopol concentration, $0.5 \%$ (w/w), was used to prepare three formulations comprising the HighCP:No $\beta \mathrm{G}$, HighCP:Low $\beta \mathrm{G}$ and the HighCP:Medium $\beta G$ formulation, respectively. Lower Carbopol concentration, $0.25 \%$ (w/w), was used to prepare the LowCP:High $\beta \mathrm{G}$ formulation. The content of $\beta \mathrm{G}$ varied from $0.25 \%$ in the HighCP:Low $\beta G, 0.5 \%$ in the HighCP:Medium $\beta G$ and $1.0 \%(w / w)$ in the LowCP:High $\beta G$ formulation, respectively. The first part of the study focused on the rheological characterization of the hydrogels and the fluid affinity testing. All formulations were confirmed to be stable gels; the $\beta G$ was shown to augment the gel strength by increasing the yield strength of the gel in a dose dependent manner. The stability of the formulations containing either Carbopol alone or in a combination with $\beta G$ did not deteriorate over 26 weeks, and the fluid donation and absorption study indicated a fluid donation profile, which favors healing of dry wounds. The in vivo efficacy of the formulations, evaluated in the modified diabetic male mice ( $\mathrm{db} / \mathrm{db}$ mice), showed that Carbopol alone was unable to induce improved healing and caused adverse reactions in some wounds. The inclusion of $\beta \mathrm{G}$ increased the epithelialization and wound contraction in the $\mathrm{db} / \mathrm{db}$ mice when given at high $\beta \mathrm{G}$ :Carbopol ratio. The positive effect of $\beta \mathrm{G}$ was, however, not sufficient to counteract the adverse effect of Carbopol, thus a more suitable thickening agent should be investigated for further development of a sprayable wound care product.
\end{abstract}

Key words: beta-glucan; Carbopol; db/db mice; rheology; hydrogel; wound healing 


\section{Introduction}

Delayed and incomplete wound healing represents a significant health problem worldwide in an increasingly elderly population suffering from medical conditions, such as diabetes, that contribute to a higher prevalence of chronical wounds (Han and Ceilley, 2017). The demand for suitable dressings to facilitate the biological healing process is therefore huge, despite of a large increase in the number of available newer dressings in the last years (Caló and Khutoryanskiy, 2015). The choice of wound dressing should be evidence-based (King et al., 2017; Frykberg and Banks, 2015), and differs according to the underlying pathology, as well as the state of the wound (the stage of healing, wound- size, -depth and-location). Thus, there is no dressing that is optimal for all wounds (Powers et al., 2013). Ideally, the wound dressings should protect and stabilize the wound, providing an optimal moist environment where water is donated to dry wounds and excess exudate is absorbed in wet wounds (Caló and Khutoryanskiy, 2015; Boateng et al., 2008). The applied dressing should also be biocompatible, non-toxic, gentle to the skin upon removal and preferably stimulate the healing process through an active healing ingredient (Caló and Khutoryanskiy, 2015).

An optimal format could be a sprayable wound dressings (Laila et al., 2011; Jones et al., 2006). Such a format would have the advantages of multiple-use containers, minimal discomforts during application, easy and quick administration onto the wound, provides a big surface contact area of the formulation, and easier access to deeper wounds. Moreover, an aerosol system should provide a protective gel film on the wound with an optimal wound healing environment, which can be covered by a secondary bandage. To form sprayable wound dressing, and assure its optimal performance, it is crucial to select the agent with characteristics suitable for spraying such as shear thinning properties. This allows for the spray to be pumped through a spray nozzle, but maintaining a firm gel layer on the skin or in the wound. One group of gel-forming vehicle that has favorable characteristics for use in spray delivery is carbomers.

Carbomers are a commercially available group of synthetic polymers made from acrylic acids, which are crosslinked allyl sucrose or allyl ethers of pentaerythritol. These types of polymers are well-known pharmaceutical ingredients in many oral, mucosal and ophthalmic drug formulations, as well as in skin products (Lubrizol, 2017). Due to their synthetic origin, the polymers are well characterized and the risk of containing contaminants is reduced as compared 
to polymers isolated from natural origin. Carbopol 971P NF (Carbopol) was chosen as the thickening agent, due to several attractive features such as: low viscosity compared to other carbomers, low toxicity, high transparency and relatively good ion tolerance (Lubrizol, 2017). Considering the shear thinning/pseudoplastic properties of Carbopol, and the physical limitation of spray actuators as the delivery device for the hydrogel, the 971P NF was considered to be the optimal choice.

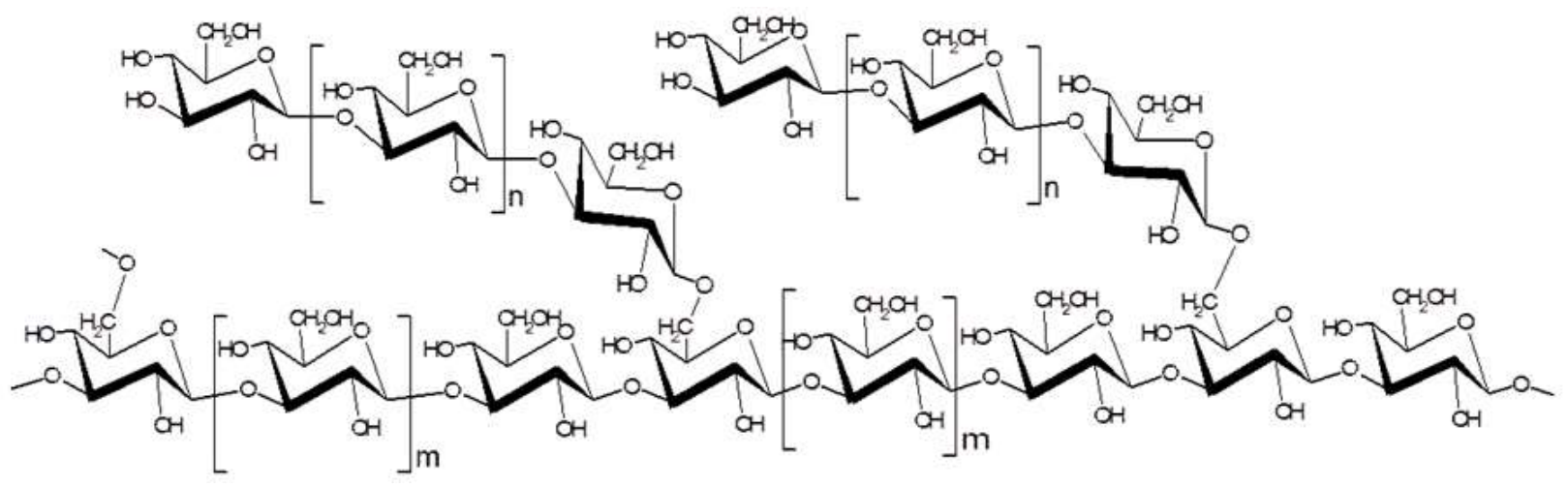

Figure 1. Beta-1,3 glucan with 1,6 -branching sidechain of glucose monomers.

An active wound healing ingredient is beta-glucans (Zykova et al., 2014) which forms a heterogeneous group of polysaccharides build from $\beta$-glucose monomers (Figure 1), where the primary structure, molecular weight, branching and polymer charge influence the biological activity and solubility of the $\beta$-1,3-glucans (Soltanian et al., 2009). Beta-glucans are currently used in a number of applications ranging from skin care, medicine, and as food supplements due to their immunological (Stier et al., 2014; Novak and Vetvicka, 2008) and anti-inflammatory effects (Du et al., 2015). In this study, we have used a soluble $2.5 \%(\mathrm{w} / \mathrm{v})$ beta-glucan $(\beta \mathrm{G})$, containing $\beta-1,3 / 1,6$ glucan extraction and purification from the cell walls of Baker's yeast (Saccharomyces cerevisiae). $\beta \mathrm{G}$ is reported to be a potent inducer of innate immune mechanisms both in animal models as well as in human cell cultures (Engstad et al., 2002; Engstad and Robertsen, 1994). Regarding topical application of beta-glucans, various skin diseases have been suggested to potentially benefit from the multiple actions of these compounds (i.e. antioxidative, anti-inflammatory, regeneration effect, immunomodulation, radio-protective, moisturizing) (Jesenak et al., 2015), and it topical application in dermatology is increasing 
(Jesenak et al., 2015). Mechanistically, beta-glucan is recognized by innate immune receptors as a Pathogen-Associated Molecular Pattern (PAMP). Recognition of PAMPs primes the innate immune system, and subsequently the adaptive immune system, preparing it to fight off infections. Macrophages, dendritic cells and neutrophils recognize beta-glucan when the molecule binds to Dectine-1 receptor, which triggers phagocytosis, respiratory burst and inflammatory response (Ma and Underhill, 2013). In wounds, 1,3-linked beta-glucan have been shown to enhance migration and proliferation of keratinocytes, which is vital for wound closure in humans, thereby accelerating the wound healing (van den Berg et al., 2014).

In the present work, we attempt to develop a sprayable hydrogel wound dressing, with $\beta G$ as an active ingredient, Carbopol 971P NF as a gel vehicle and glycerol as a stabilizing agent.

Finally, four different hydrogel formulations were tested in the diabetic mice wound model. The wound healing effect was compared to water and a growth factor cocktail as negative and positive control, respectively.

\section{Materials and methods}

\subsection{Materials}

Carbopol $^{\circledR}$ 971P NF (Carbopol) was a gift from The Lubrizol Corporation (Ohio, USA). Milli-Q water was produced using Q-Pod ${ }^{\circledR}$ by Merck Millippore (Billerica, MA, USA). The 1,2,3propanetriol glycerol was purchased from VWR (Fontenay sous Bois, France). Soluble beta1,3/1,6-glucan ( $\beta \mathrm{G} ; 2.5 \% \mathrm{w} / \mathrm{w}$ ) was a gift from Biotec BetaGlucans AS (Tromsø, Norway). Sodium hydroxide was purchased from Merck KGaA (Darmstadt, Germany). Gelatin from porcine skin and hydroxypropyl methylcellulose (HPMC) were acquired from Sigma-Aldrich (Taufkirchen, Germany). Acto ${ }^{\mathrm{TM}}$ Agar was purchased from BD (Le Pont de Claix, France). IsoFlo ${ }^{\circledR}$ was from Zoetis (London, UK), and Vetergesic ${ }^{\circledR}$ from Alstoe Animal Health (Espoo, Finland). Platelet-derived growth factor-BB and Transforming Growth Factor-alpha was purchased from PeproTech EC Ltd (London, UK). 


\subsection{Preparation of Carbopol hydrogels}

Four different sprayable hydrogel formulations were prepared; three of those formulations contained various concentrations of Carbopol, $\beta \mathrm{G}$ and glycerol, whereas one formulation contained no $\beta \mathrm{G}$ (Table 1). The polymer (Carbopol and $\beta \mathrm{G}$ ) concentrations applied were selected to assure that hydrogels were sprayable: the sprayable polymer concentrations are presented in Table S1 (in Supplement S1)

The hydrogel formulations were prepared by wetting the Carbopol polymer with glycerol prior to adding water. The Carbopol-glycerol-water mixture was left to swell overnight. The following day, $\beta \mathrm{G}$ was heated to $50^{\circ} \mathrm{C}$ before mixing it at low shear with the concentrations listed in Table 1. Finally, $\mathrm{pH}$ was adjusted to 5.0 using $1 \mathrm{M} \mathrm{NaOH}$, and all formulations were autoclaved at 121 ${ }^{\circ} \mathrm{C}$ for 20 minutes.

Table 1. Hydrogel formulations investigated

\begin{tabular}{cccc}
\hline Formulation name & $\begin{array}{c}\text { Carbopol content } \\
(\%, \mathrm{w} / \mathrm{w})\end{array}$ & $\begin{array}{c}\beta \mathrm{G} \text { content } \\
(\%, \mathrm{w} / \mathrm{w})\end{array}$ & $\begin{array}{c}\text { Glycerol content } \\
(\%, \mathrm{w} / \mathrm{w})\end{array}$ \\
\hline HighCP:NoßG & 0.50 & - & 10 \\
HighCP:Low $\beta \mathrm{G}$ & 0.50 & 0.25 & 10 \\
HighCP:Medium $\beta \mathrm{G}$ & 0.50 & 0.50 & 10 \\
LowCP:High $\beta \mathrm{G}$ & 0.25 & 1.00 & 10
\end{tabular}

\subsection{Rheological characterization}

The rheological characterizations were performed using a Discovery HR-2 Hybrid Rheometer (TA Instruments, New Castle, DE, USA) equipped with $40 \mathrm{~mm}$ plate geometry. The plate was compressed to a gap of $1050 \mu \mathrm{m}$ against the platform, excess gel removed and the plate geometry lowered to $1000 \mu \mathrm{m}$. Two measurement protocols were carried out; namely the oscillation time sweep protocol and amplitude sweep protocol, measuring the storage modulus $\left(G^{\prime}\right)$ and the loss modulus (G') of the unbroken gel strength, and the yield stress, respectively. All samples were loaded and soaked for $120 \mathrm{sec}$ to provide a stable test temperature of $25^{\circ} \mathrm{C}$ during measurements. The oscillation time sweep protocol was carried out with oscillation 
displacement of $1.0 \mathrm{e}^{-3} \mathrm{rad} / 1.0 \mathrm{~Hz}$ for $60 \mathrm{sec}$. After the oscillation time sweep protocol, the gel was left to rest for $30 \mathrm{sec}$ before performing the amplitude sweep protocol. The amplitude sweep protocol was performed at $1.0 \mathrm{~Hz}$ with the torque range from 100 to $10000 \mu \mathrm{N} \cdot \mathrm{m}$ with an increment of $100 \mu \mathrm{N} \cdot \mathrm{m}$. Results were processed by the Trios software v. 3.2.0.3877 (TA Instruments, New Castle, DE, USA) to obtain the different hydrogel`s phase angle and yield point using the oscillation time sweep and the amplitude sweep protocol, respectively.

To characterize the formulations considering the skin temperature the oscillation sweep protocol was performed both at $32{ }^{\circ} \mathrm{C}$ and $25^{\circ} \mathrm{C}$ to determine the relative difference in yield point.

\subsection{Viscosity measurements}

Viscosity was measured using a DV-II+ Pro Viscometer equipped with Rheocalc V3.2 by Brookfield Engineering Labs (Lorch, Germany). The test formulations were placed in the small sample adaptor with a flow jacket for temperature control, and left to soak for 15 minutes at 25 ${ }^{\circ} \mathrm{C}$. Samples were tested with either the SC4-31 or SC4-25 spindle, depending on the sample viscosity. Higher viscosity samples were tested with the SC4-25 spindle, which requires $16 \mathrm{ml}$ of sample, and lower viscosity samples were tested on the SC4-31 spindle requiring $9 \mathrm{ml}$ of sample. The IPC (Institute for Interconnecting and Packaging Electronic Circuits) paste model was used to determine the $10 \mathrm{rpm}$ viscosity (Equation 1) (Brar et al., 2007).

\section{Equation 1.}

$$
\eta=\mathrm{kR}^{n}
$$

$\eta=$ Viscosity $(\mathrm{cP})$

$\mathrm{k}=$ Consistency multiplier

$\mathrm{R}=$ Rotational speed

$\mathrm{n}=$ Shear sensitivity factor 


\subsection{Fluid affinity}

The hydrogel's water donation and water absorption were measured according to the EU standard EN 13726-1:2002 (Standard, 2002). This test emulates dry and exuding wounds by using gelatin $(35 \% \mathrm{w} / \mathrm{w})$ and agar $(2 \% \mathrm{w} / \mathrm{w})$, respectively, made in "Solution A" (142 mmol $\mathrm{Na}_{2}^{+}, 2.5 \mathrm{mmol} \mathrm{Ca} 2^{+}$), that is emulating ion concentration of the blood. The experiment was carried out in the pre-prepared $60 \mathrm{ml}$ syringes, purchased from B. Braun Melsungen (Hessen, Germany), with their plunger drawn to the $30 \mathrm{ml}$ mark and the tip removed. The agar was heated to $121 \pm 1{ }^{\circ} \mathrm{C}$ for 20 minutes, and subsequently cooled to $60 \pm 5^{\circ} \mathrm{C}$ before it was filled into the pre-prepared syringes. The gelatin was heated to $60 \pm 1^{\circ} \mathrm{C}$ for $14 \pm 1$ hours before being filled into the pre-prepared syringes. Ten $g$ of either gelatin or agar was filled into each syringe. All agar and gelatin syringes were covered with Parafilm ${ }^{\circledR}$ to prevent condensation, and allowed to settle at $25 \pm 2{ }^{\circ} \mathrm{C}$ for three hours. After three hours the Parafilm ${ }^{\circledR}$ was removed, and syringes with the content weighed. The hydrogel formulations $(10 \pm 0.1 \mathrm{~g})$ were then filled into syringes, weighed, and covered with Parafilm ${ }^{\circledR}$. After incubating for 48 hours at $25 \pm 2{ }^{\circ} \mathrm{C}$, the Parafilm ${ }^{\circledR}$ was removed and the syringes were weighed. Upon the removal of hydrogel, the syringe, with either agar or gelatin, was weighed. The test was performed in quintuplicates, and outliers were removed using Grubbs test based on the percentage weight change (Grubbs, 1969).

\subsection{In vivo wound healing experiments in diabetic mice}

\subsubsection{Experimental animals}

The in vivo experimentation was based on the protocol described elsewhere (Hardwicke et al., 2011). Diabetic mice (BKS.Cg-m Dock7m +/+ Leprdb /J), all male, were purchased from Jackson Labs (Bar Harbour, ME, USA), and brought into the animal facilities when approximately 9-10 weeks old. The mice were allowed to acclimate for one week prior to the start of the study, where the 60 mice included in the study, were randomly divided into six experimental groups (10 mice per group) receiving four different treatment formulations (as described in Table 1). , with addition of two control groups. Animals were maintained according to the Home Office Regulations UK and the specific requirements of diabetic animals (Home Office, 2014). As positive control, a formulation containing $10 \mu \mathrm{g} /$ dose platelet-derived growth 
factor and $1 \mu \mathrm{g} /$ dose transforming growth factor alpha dissolved in $0.5 \%$ (w/v) HPMC was applied. Negative control was water. For all tested formulations, including the negative control, a volume of $50 \mu \mathrm{l}$ was administered. The treatment was scheduled to be applied on day $0,2,4,6$ and 8 for the test formulations and negative control, and the positive control treatment scheduled on day $0,1,2,3,4,5$ and 6 . The experimental setup is described in more detail in the Supplement, Table S2.

\subsubsection{Wound induction}

Wound induction took place on a day 0 . All mice were anaesthetized using isoflurane and air; 4 $\%$ isoflurane and $96 \%(\mathrm{v} / \mathrm{v})$ air for the induction of anesthesia and $2 \%$ isoflurane $98 \%(\mathrm{v} / \mathrm{v})$ air for maintenance. The skin on their left dorsal flank was shaved and cleansed. A single standardized full-thickness wound $(10 \mathrm{~mm} \times 10 \mathrm{~mm})$ was created approximately $10 \mathrm{~mm}$ from the spine. Wound was photographed with an identification plate and calibration rule. The wounds were covered with Bioclusive ${ }^{\circledR}$ film dressing, purchased from Systagenix Wound Management (Gargrave, UK) and the treatments were applied by an injection through the Bioclusive ${ }^{\mathrm{TM}}$ film using a 27-gauge needle. All mice were dosed with $75 \mu \mathrm{g} / \mathrm{kg}$ Vetergesic ${ }^{\circledR}$ post-surgery - dose volume $100 \mu$ l. Dosing was repeated every 12 hours when necessary.

\subsubsection{Wound closure assessment}

Image Pro Plus image analysis software (version 4.1.0.0, Media Cybernetics, Rockville, MD, USA) was used to calculate the wound closure from scaled wound images taken at each assessment point (day 0, 4, 8, 12, 16, 20 and 24). Three different assessments were made from the images:

(1). Open wound area: Percentage of wound area remaining with time i.e. the open area at a given time point relative to the area of the same wound at day 0 .

The wound area at Day 0-Open wound are at a given time $=$ Wound closure

(2) Wound contraction: The difference between the contracted wound area at a given time point (solid black line in Figure 2 left panel) and the original wound area (solid black line in Figure 2 
left panel, red line in Figure 2 right panel), as a percentage of the original wound area (solid black line in Figure 2 left panel, red line in Figure 2 right panel).

The wound area at Day 0 - Contraction area at given time $=$ Wound contraction

(3) Re-epithelialization: i.e. the contracted wound area at a given time (solid black line Figure 2 right panel) minus the open wound area at that given time (dotted black line Figure 2 left panel, red line in 2 right panel)

$$
\begin{aligned}
& \text { Wound contraction at given time - The wound area at given time } \\
& =\text { Re-epithelization }
\end{aligned}
$$

All wounds were visually assessed on a daily basis until day 8 - and subsequently every second day until day 24 to determine their healing status. Each wound was scored as to whether they displayed a neo-dermal tissue generation activity (healing process) or not. Each wound was assessed by two independent observers and wounds displaying healing was compared between treatment groups at each assessment point. 


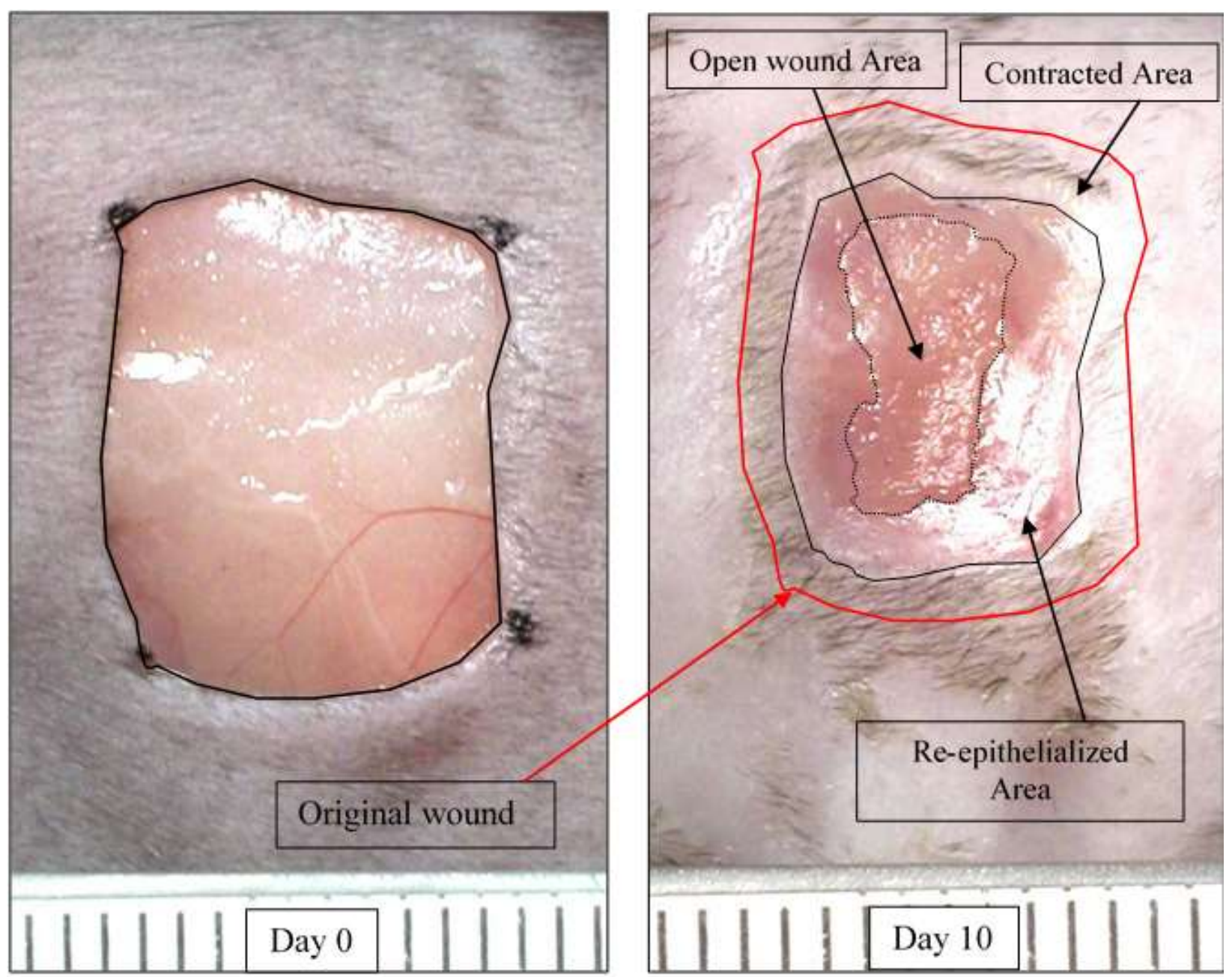

Figure 2. Images with the wound closure terminology applied in the experiments.

\subsection{Statistical analysis}

Grubbs test was used to remove outliers in the evaluation of the donation and absorption of fluids, and a two tailed t-test was used to determine the difference between time points within the groups. P values of $<0.05$ were considered as indicative of significant difference between the control and treatment group.

In the animal study determining the remaining wound area, wound contraction and reepithelization, the 2 sample non-parametric statistical test Mann-Whitney U-test was used to test for statistically significant differences between groups. P values of $<0.05$ were considered as indicative of significant difference between the control and treatment group. 


\section{Results and Discussion}

\subsection{Rheological characterization of the formulations}

All the formulations were confirmed to be gels, as the storage modulus $\left(G^{\prime}\right)$ was higher than the loss modulus (G') at $25^{\circ} \mathrm{C}$, represented by a phase angle below $45^{\circ}$ during the time sweep measurements (Figure 3A). These results also indicate that the inclusion of $\beta \mathrm{G}$ increases the hydrogels firmness at rest more than Carbopol.

The increased amount of $\beta G$ augmented the gel strength by increasing the yield strength of the gel in a dose dependent manner. This stabilizing effect of $\beta \mathrm{G}$ was more pronounced at $25^{\circ} \mathrm{C}$ than at $32{ }^{\circ} \mathrm{C}$, as the yield point was higher at $25^{\circ} \mathrm{C}$ than at $32{ }^{\circ} \mathrm{C}$ (Table 2). The results indicate that $\beta \mathrm{G}$ increases the strength of the gels, and that this effect was more pronounced at $25{ }^{\circ} \mathrm{C}$, as the ratio of yield stress $\left(25 / 32^{\circ} \mathrm{C}\right)$ was increasing with an increasing $\beta \mathrm{G}$ content.

The results from the oscillation sweep measurements (Table 2) showed that $0.5 \%(\mathrm{w} / \mathrm{w})$ Carbopol gel had a yield point of 21.6 Pa, whereas $2.5 \%(\mathrm{w} / \mathrm{v}) \beta \mathrm{G}$ had a yield point of $21.0 \mathrm{~Pa}$ at $25^{\circ} \mathrm{C}$. Thus the relative strength of Carbopol was higher than that of $\beta \mathrm{G}$.

The HighCP:Low $\beta$ G formulation, containing $0.5 \%$ Carbopol and $0.25 \% \beta G$ had a yield point of 55.0 $\mathrm{Pa}$. It seems that Carbopol and $\beta \mathrm{G}$ have a synergic effect rather than an additive effect on the yield point. Carbopol is known as a good stabilizer for a topical formulations (Kim et al., 2003; Kumbhar et al., 2013). Out results (Table 2) shows that gelling properties of Carbopol is more resistant to the higher temperature than $\beta \mathrm{G}$, as the ratio yield stress $\left(25 / 32{ }^{\circ} \mathrm{C}\right)$ was increasing with increasing $\beta G$ content, and varied from $190.3 \%$ to $103.9 \%$ for the $2.5 \%$ (w/v) $\beta \mathrm{G}$ and the HighCP:NoßG formulation, respectively (Table 2). 
Table 2. The effect of temperature and formulation on the yield point $(\mathrm{Pa})$ using oscillation sweep $(n=3)$

\begin{tabular}{|c|c|c|c|c|c|}
\hline Temperature & $\begin{array}{c}2.5 \%(\mathrm{w} / \mathrm{v}) \\
\beta \mathrm{G}^{1)}\end{array}$ & $\begin{array}{l}\text { HighCP: } \\
{\text { No } \beta G^{2}}^{2}\end{array}$ & 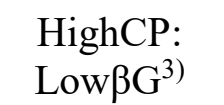 & $\begin{array}{c}\text { HighCP: } \\
\text { Medium } \beta G^{4)}\end{array}$ & $\begin{array}{l}\text { LowCP: } \\
\text { High } \beta G^{5)}\end{array}$ \\
\hline $25^{\circ} \mathrm{C}$ & $\begin{array}{c}21.00 \pm 1.61 \\
\mathrm{~Pa}\end{array}$ & $\begin{array}{c}21.60 \pm 0.60 \\
\mathrm{~Pa}\end{array}$ & $\begin{array}{c}55.00 \pm 3.43 \\
\mathrm{~Pa}\end{array}$ & $\begin{array}{c}73.00 \pm 1.20 \\
\mathrm{~Pa}\end{array}$ & $\begin{array}{c}84.00 \pm 3.91 \\
\mathrm{~Pa}\end{array}$ \\
\hline $32{ }^{\circ} \mathrm{C}$ & $\begin{array}{c}11.00 \pm 2.15 \\
\mathrm{~Pa}\end{array}$ & $\begin{array}{c}20.80 \pm 0.56 \\
\mathrm{~Pa}\end{array}$ & $\begin{array}{c}47.80 \pm 2.76 \\
\mathrm{~Pa}\end{array}$ & $\begin{array}{c}59.70 \pm 2.75 \\
\mathrm{~Pa}\end{array}$ & $\begin{array}{c}66.10 \pm 3.59 \\
\mathrm{~Pa}\end{array}$ \\
\hline $\begin{array}{c}\text { Ratio yield point } \\
\left(\left(25 / 32^{\circ} \mathrm{C}\right) * 100 \%\right)\end{array}$ & $190.3 \%$ & $103.9 \%$ & $115.0 \%$ & $122.1 \%$ & $127.1 \%$ \\
\hline
\end{tabular}

\subsection{Stability of the formulations}

The stability of the hydrogels was investigated at $25^{\circ} \mathrm{C}$, measuring the oscillating phase angle (Figure 3A) and the yield stress (Figure 3B) at 5 different time points between one and 26 weeks post-production, using the oscillation time sweep- and amplitude sweep protocol, respectively. Only small variations at different time points within each group were detected; the variation in the yield point for the same formulation was less than $10 \mathrm{~Pa}$ for all formulations except the values for the first week (Figure 3B). The increase in the yield point from the first week after the production to the second can be contributed to the delayed onset of 3D gel-network forming by polymer aggregation (Ingebrigtsen et al., 2016). Since this difference was not seen in the formulation containing only Carbopol, glycerol and water, the effect is most likely due to the aggregated nature of the $\beta \mathrm{G}$ molecule as a result of the degree of polymerization and branch distribution (Qin et al., 2013).

As described in Table 1, three of the formulations, namely HighCP:No $\beta G$, HighCP:Low $\beta G$ and HighCP:Medium $\beta G$, had the same Carbopol content $(0.5 \%(\mathrm{w} / \mathrm{w}))$, whereas the $\beta \mathrm{G}$ content was $0.0 \%(\mathrm{w} / \mathrm{w}), 0.25 \%(\mathrm{w} / \mathrm{w})$ and $0.5 \%(\mathrm{w} / \mathrm{w})$, respectively. For the High $\beta \mathrm{G}$ formulation the 
amount of Carbopol was $0.25 \%(\mathrm{w} / \mathrm{w})$ and the amount of $\beta \mathrm{G}$ was $1.0 \%(\mathrm{w} / \mathrm{w})$. Thus, the yield point increased with increasing $\beta \mathrm{G}$ content (Figure $3 \mathrm{~B}$ ); the strength of the gel was higher when more $\beta G$ was included in the formulation. Similarly to the increasing strength corresponding to the higher content of $\beta \mathrm{G}$ in the gel, the gel elasticity was also improved in the time sweep protocol with the increasing $\beta \mathrm{G}$ content (Figure 3A).

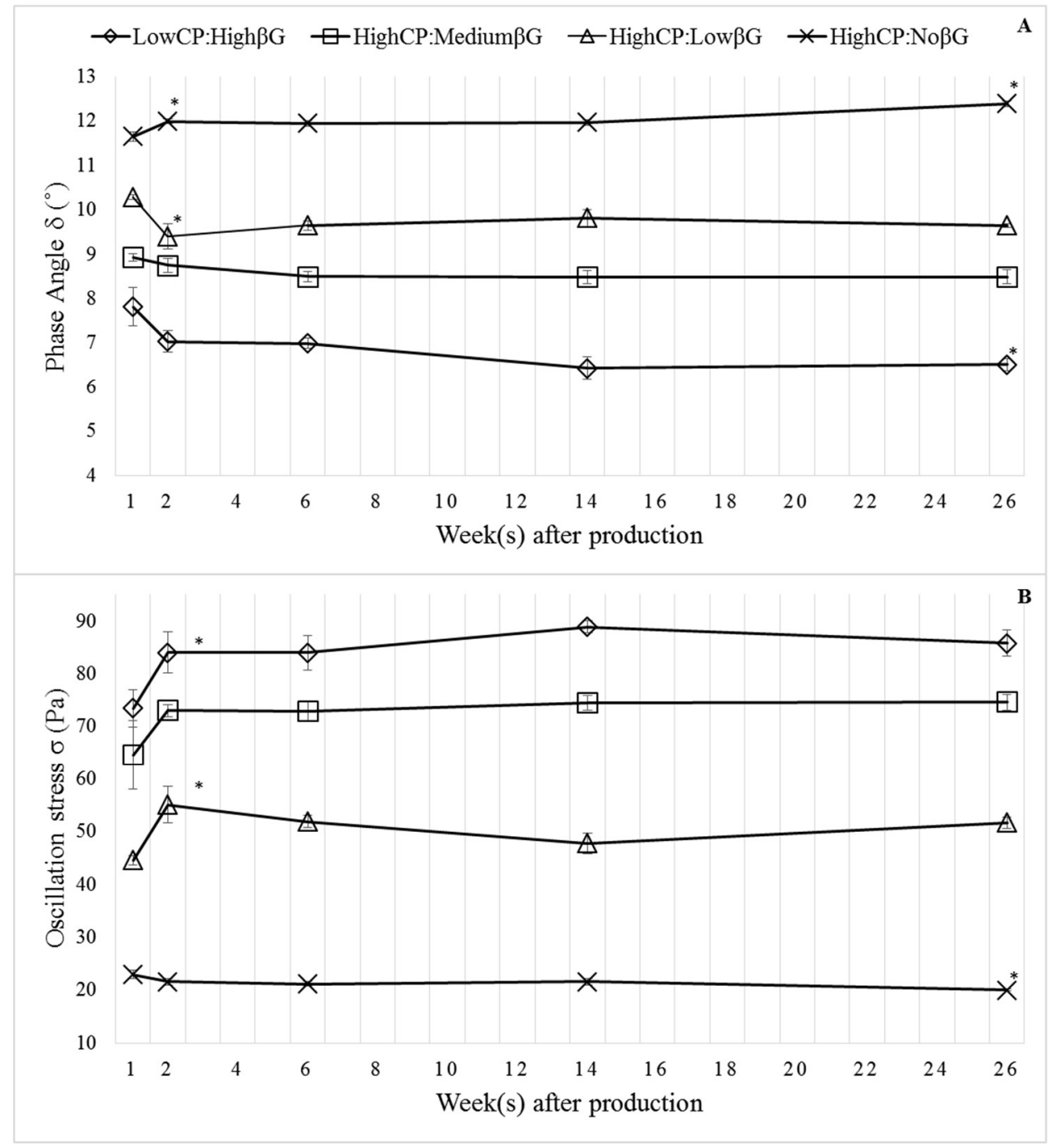

Figure 3. The 26-weeks rheological stability of the four hydrogel formulations A) Oscillation time sweep stability testing $(n=3)$. B) The amplitude sweep stability testing $(n=3)$. The asterisks in week 2 and 26 denotes statistical difference between week 1 and 2, and 2 and 26, respectively with $\mathrm{p}<0.05(\mathrm{n}=3)$. All formulations contained $10 \%(\mathrm{w} / \mathrm{w})$ glycerol, and varying concentrations of Carbopol 971P (CP) and Soluble beta-1,3/1,6-glucan ( $\beta$ G): LowCP:HighßG: $0.25 \%$ (w/w)

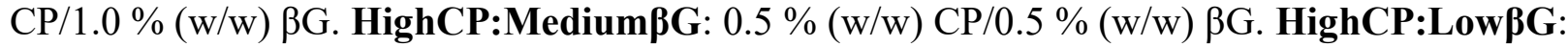
$0.5 \%(w / w)$ CP/0.25 \% (w/w) $\beta$ G. HighCP:NoßG: $0.5 \%(w / w) ~ C P$. 


\subsection{Viscosity measurements}

The viscosity of the different formulations applied in the in vivo wound healing study, including the positive control $(0.5 \% \mathrm{w} / \mathrm{w})$ HPMC without growth factor, was measured at $25^{\circ} \mathrm{C}$, and the viscosity at $10 \mathrm{rpm}$ (Figure 4) was calculated from the measurements using the IPC Paste model (Sharma et al., 2014). The viscosity of the positive control was $22 \pm 0.1 \mathrm{cP}$ and the viscosity of the negative control (water) is known to be $0.89 \mathrm{cP}$ at $25{ }^{\circ} \mathrm{C}$ (Crittenden et al., 2012). The viscosity increased in a dose dependent manner with regards to the total polymer content (Carbopol and $\beta G)$ in the formulation.

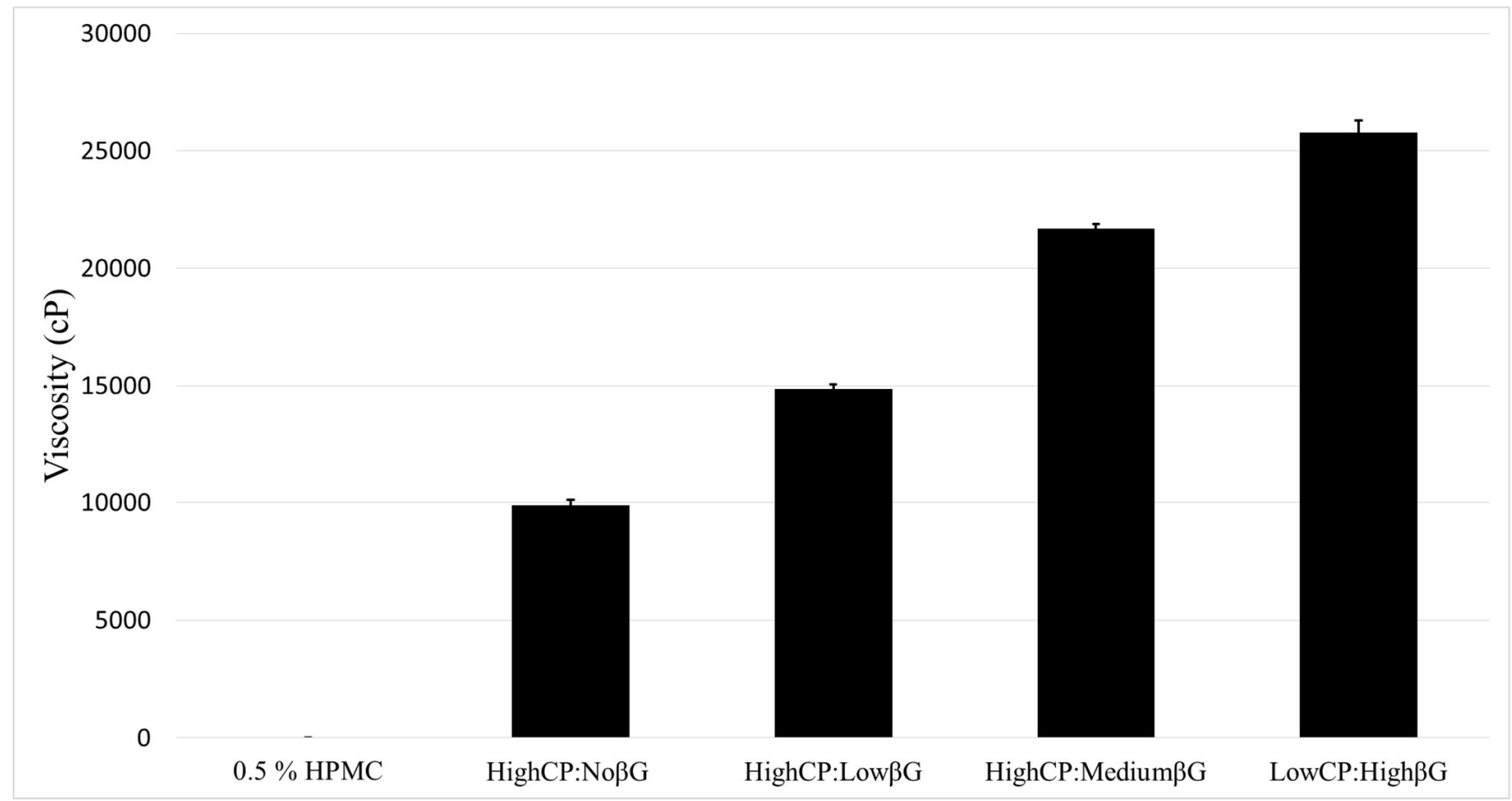

Figure 4. Viscosity of four hydrogel formulations and the positive control in the mice study. Viscosity at $10 \mathrm{rpm}$ were calculated using the IPC paste model $(\mathrm{n}=3)$. The polymer composition of the formulations in MilliQ-water: Positive control: $0.5 \%(\mathrm{w} / \mathrm{w})$ hydroxypropyl methylcellulose (HPMC). All formulations, except the HPMC formulation, contained $10 \%$ $(\mathrm{w} / \mathrm{w})$ glycerol, and varying concentrations of Carbopol 971P (CP) and Soluble beta-1,3/1,6glucan ( $\beta \mathrm{G})$ : LowCP:HighßG: $0.25 \%(\mathrm{w} / \mathrm{w}) \mathrm{CP} / 1.0 \%(\mathrm{w} / \mathrm{w}) \beta \mathrm{G}$. HighCP:Medium $\beta$ : $0.5 \%$ $(\mathrm{w} / \mathrm{w}) \mathrm{CP} / 0.5 \%(\mathrm{w} / \mathrm{w}) \beta \mathrm{G}$. HighCP:Low $\beta G$ : $0.5 \%$ (w/w) CP/0.25 \% (w/w) $\beta \mathrm{G}$.

HighCP:NoßG: $0.5 \%(\mathrm{w} / \mathrm{w}) \mathrm{CP}$. 


\subsection{Fluid affinity of the hydrogel formulations}

Amorphous hydrogels might encourage wound healing through several mechanisms; supplying moisture to dry wounds, promoting rehydration of non-viable tissue, functioning as debriding agents, and by providing optimal moist condition for the cell types involved in wound closure (Powers et al., 2016; Lay-Flurrie, 2004). Supplying the wound with enough moisture accelerates the healing; however providing too much moisture can have negative effect on the tissue, as exemplified by maceration of the wound edges (i.e. erosion of the peri-wound tissue) (Powers et al., 2016; Schultz et al., 2003). The ability of our formulations to donate and absorb water were simulated using gelatin and agar, a water- absorbent and acceptor, respectively, according to the standard "EN 13726-1:2002 Test methods for primary wound dressings- Part 1: aspects of absorbency" (Standard, 2002). Results are shown in Figure 5. All Carbopol formulations exhibited a higher donation than absorbance of liquids. These results might indicate a higher stability with increasing content of $\beta \mathrm{G}$, as the LowCP:High $\beta \mathrm{G}$ formulation is the only formulation that shows no statistical difference in both absorption and donation characteristics between the two measurements made after one and nine weeks storage of the gels, respectively. However, such a difference in stability was not confirmed by the rheological behavior of the gels investigated over 26 weeks (Figure 3). Use of amorphous hydrogel, such as the Carbopolcontaining formulations tested in this study, is recommended for treatment of the shallow and deep open wounds e.g. pressure sores, leg ulcers, surgical and malignant wounds, partial thickness burns, scalds and lacerations (Jones and Vaughan, 2005). 


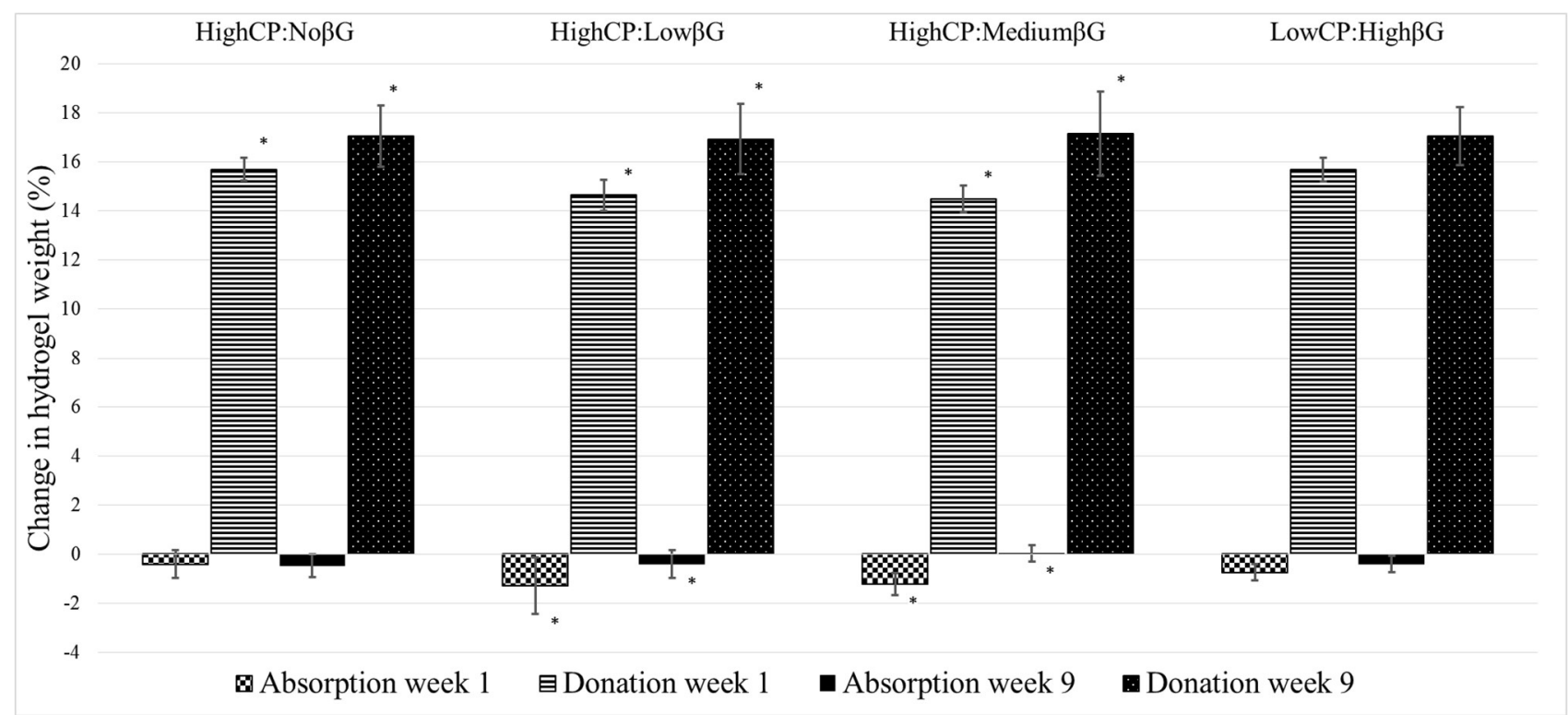

Figure 5. Absorbency and donation characteristics of the five hydrogel formulations after one and nine weeks of storage. Asterisk denotes statistical differences $(p<0.05)$ between week one and week nine, using a two tailed t-test $(\mathrm{n}=5)$. All formulations contained $10 \%(\mathrm{w} / \mathrm{w})$ glycerol, and varying concentrations of Carbopol 971P (CP) and Soluble beta-1,3/1,6-glucan $(\beta \mathrm{G})$ :

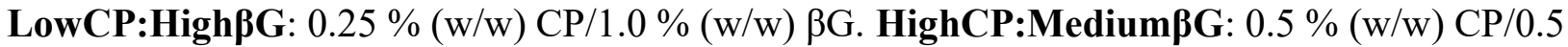

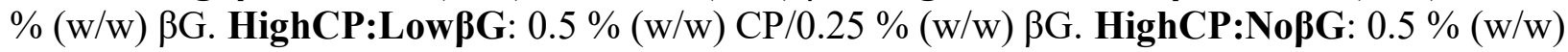
$\mathrm{CP}$.

\subsection{In vivo wound healing in mice}

\subsubsection{Wound model}

To predict the efficacy of the hydrogel formulations in human wound healing, and the immunemodulating effect of the hydrogel and its active component, the formulations were tested in diabetic mice. The mechanisms of wound healing in the rodent models differ from humans in that they heal by both contraction of the wound margins and re-epithelialization (Abdullahi et al., 2014). As such, the usefulness of mice models for wound healing have been questioned as the mechanisms for wound closure in human mainly depend on re-epithelialization. However, it has recently been demonstrated that the wound healing in $\mathrm{db} / \mathrm{db}$ mice depend equally on both contraction and re-epithelialization (Chen et al., 2015), thus making it a useful model for wound healing studies still. 
Previously, commercial hydrogel formulations containing the same $\beta \mathrm{G}$ as in this study, have been tested in the $\mathrm{db} / \mathrm{db}$ mouse model (Skjæveland and Engstad, 2013). The study showed a statistically significant $(\mathrm{p}<0.05)$ better angiogenesis and wound contraction with $\beta \mathrm{G}$ and carrier (carboxymethyl cellulose) as compared to treatment with the carrier alone or water control (pers. comm.). However, the concentration used in the study was $2 \%(\mathrm{w} / \mathrm{w})$, whereas in this study we tested a maximum $\beta \mathrm{G}$ concentration of $1 \%(\mathrm{w} / \mathrm{w})$ only. The design of the study did not allow the end product as a spray delivery device to be tested, since the gel was injected under a polyurethane dressing. Thus, it should be noted that the occlusive bandages alone is known to accelerate the wound healing by maintaining a moist environment in the wound, as compared to an open wound without any dressing (Hinman and Maibach, 1963; Winter, 1962) .

\subsubsection{Wound closure, contraction and re-epithelization}

Wound closure (expressed as \% of open wound area relative to the wound area measured at wounding) results from the combined effects of wound contraction (the inward movement of marginal tissue) and re-epithelialization (wound resurfacing by the inward migration of epithelial cells) (Wong et al., 2011). Wound closure over time was a consequence of both processes. Since the extent of contraction can differ between the treatment groups, the level of contraction and its impact on the re-epithelialization, particularly at the later time points, was considered. Positive control treatment was found to significantly $(\mathrm{p}<0.05)$ accelerate the wound closure process compared to the water treatment (Figure 6). No peri-wound damage was recorded with neither water control treatment nor with the positive controls, and no significant difference in the level of weight loss of the animals were observed $(\mathrm{p}<0.05)$. As shown in Figure 6 , the four formulations HighCP:Low $\beta$ G, HighCP:Medium $\beta$ G, LowCP:High $\beta$ G and HighCP:No $\beta G$, had no promotional effect on the wound closure relative to water treatment. For some formulations even deleterious effects were observed. The last application of the test formulations on day 8 was withheld due to adverse reaction (Table S2, in supplements). Also, 7 out of the 60 animals in treatment were euthanized before the end of the study, do to animal welfare reasons, i.e. the lack of wound healing (for more details: Supplement S4, Table S3). The adverse effects observed included oedema, ischemia, apparent loss of tissue viability and erosion of the peri-wound skin (maceration); these side effects became evident within the first 4 days of treatment. Photographs 
representing the adverse reactions (such as edema, ischemia etc.) and the wound healing progression observed, are provided in the supplementary information, Figure S1 to S3.

Comparing the four Carbopol formulations, the treatment with the LowCP:High $\beta$ G formulation resulted in the highest re-epithelialization from day 12 onwards (Figure 8). Treatment with LowCP:High $\beta$ G resulted in significantly higher levels of wound re-epithelialization relative to HighCP:Medium $\beta G$ on days 8 and 20 ( $(\mathrm{p}<0.05)$, relative to HighCP:Low $\beta G$ on days 12 to 24 $(p<0.05)$ and relative to Carbopol at all time-points $(p<0.05)$. These enhanced contractions indicate an improvement in the granulation tissue function; which may in turn be explained by an increase in the amount of granulation tissue formed, an increase in the speed at which it is formed, or increased contractile capacity of the tissue (Greenhalgh et al., 1990). With the exception of LowCP:High $\beta \mathrm{G}$, the experimental formulations had little or no positive impact on the wound contraction relative to water-treatment (Figure 7). However, LowCP:High $\beta G$ treatment increased contraction significantly $(\mathrm{p}<0.05)$ compared to water treatment on days 20 and 24 .

Re-epithelialization peaked around day 16 in the positive control-treated group; after which time it decreased (Figure 8). The reduction in re-epithelialization (normally after day 16) is an artefact. This is due to the shrinkage of the underlying neo-dermal tissue, due to wound contraction, which leads to compaction of the neo-epithelium on the wound surface (Ehrlich and Hunt, 2012). The positive control group displayed the greatest peak in re-epithelialization with significantly higher levels $(\mathrm{p}<0.05)$ than all other treatments. Control wounds treated with water, re-epithelialized slowly, but progressively, until day 24. The formulations containing Carbopol re-epithelized slower than water, however, the inclusion of $\beta G$ increased the re-epithelialization as compared to HighCP:No $\beta$ G (Figure 8). The low rate of epithelialization seen in Figure 8, in combination with the remaining open wound (Figure 6) suggest that the wound healing in the groups treated with the Carbopol containing formulation are, to a larger extent, dependent on the contraction of the panniculus carnosus rather than regeneration of tissue (Abdullahi et al., 2014). However, the mechanism behind adverse reactions observed for Carbopol hydrogels remains to be explored and explained.

Of the four test Carbopol formulations, the formulation with the highest $\beta \mathrm{G}$ concentration (LowCP:High $\beta G$ ) did not give side effects such as ischemia and maceration, and demonstrated a 
small, non-significant trend toward increased wound closure relative to the water (and the other spray formulations) from day 8 onwards (Figure 6).

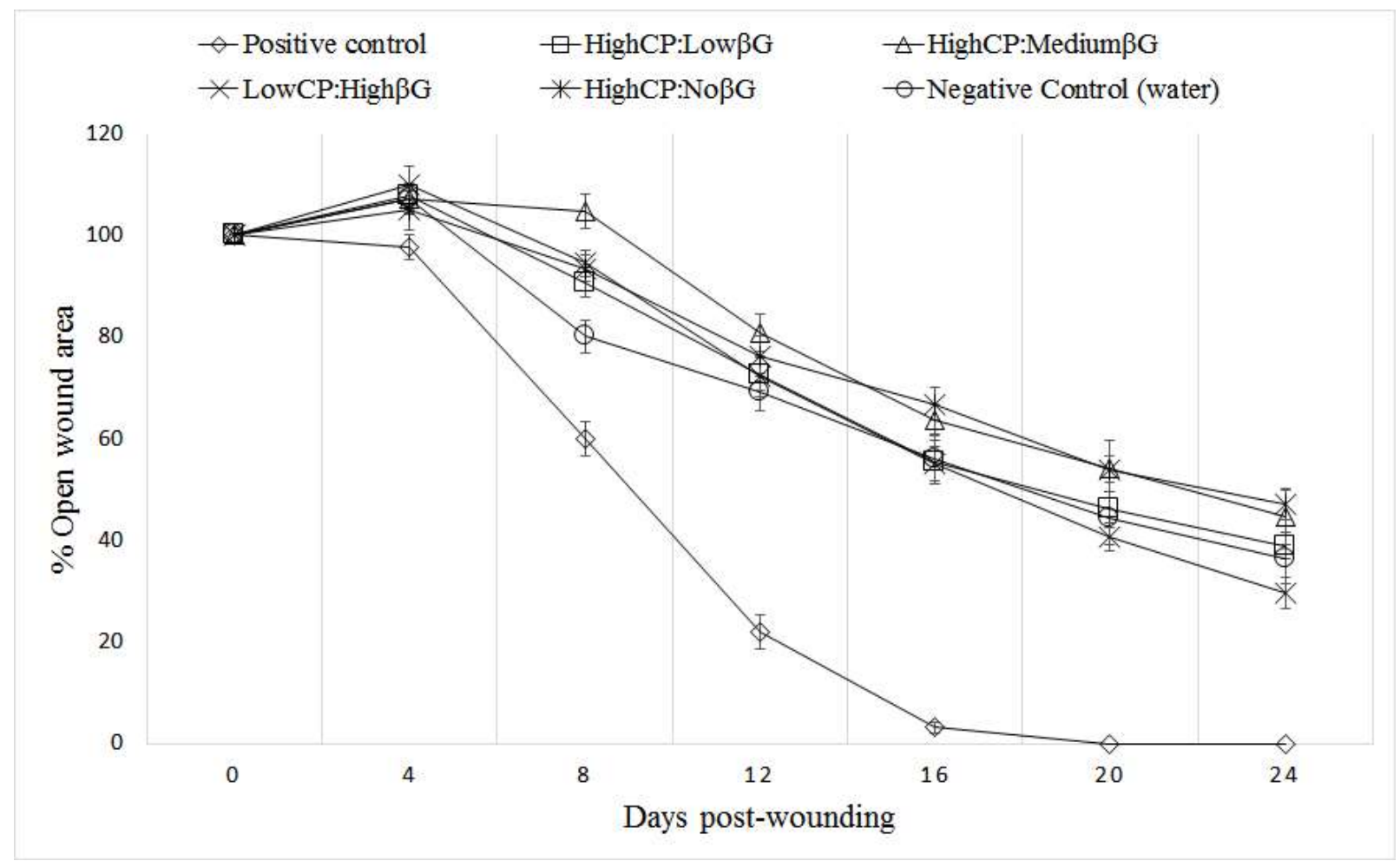

Figure 6. The relative wound closure after different treatments $( \pm \operatorname{sem})(n=10)$. Composition of the formulations in MilliQ-water: Positive control: $10 \mu \mathrm{g} / \mathrm{dose}$ platelet-derived growth factor and $1 \mu \mathrm{g}$ /dose transforming growth factor alpha in $0.5 \%(\mathrm{w} / \mathrm{v})$ hydroxypropyl methylcellulose $0.5 \%(\mathrm{w} / \mathrm{w})$. All formulations, except control formulations, contained $10 \%(\mathrm{w} / \mathrm{w})$ glycerol, and varying concentrations of Carbopol 971P (CP) and Soluble beta-1,3/1,6-glucan ( $\beta \mathrm{G})$ :

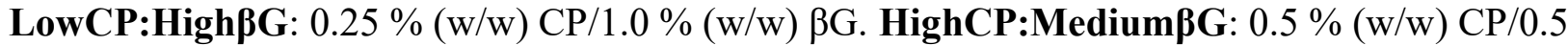
$\%$ (w/w) $\beta$ G. HighCP:LowßG: $0.5 \%$ (w/w) CP/0.25 \% (w/w) $\beta$ G. HighCP:NoßG: $0.5 \%$ (w/w) $\mathrm{CP}$. 


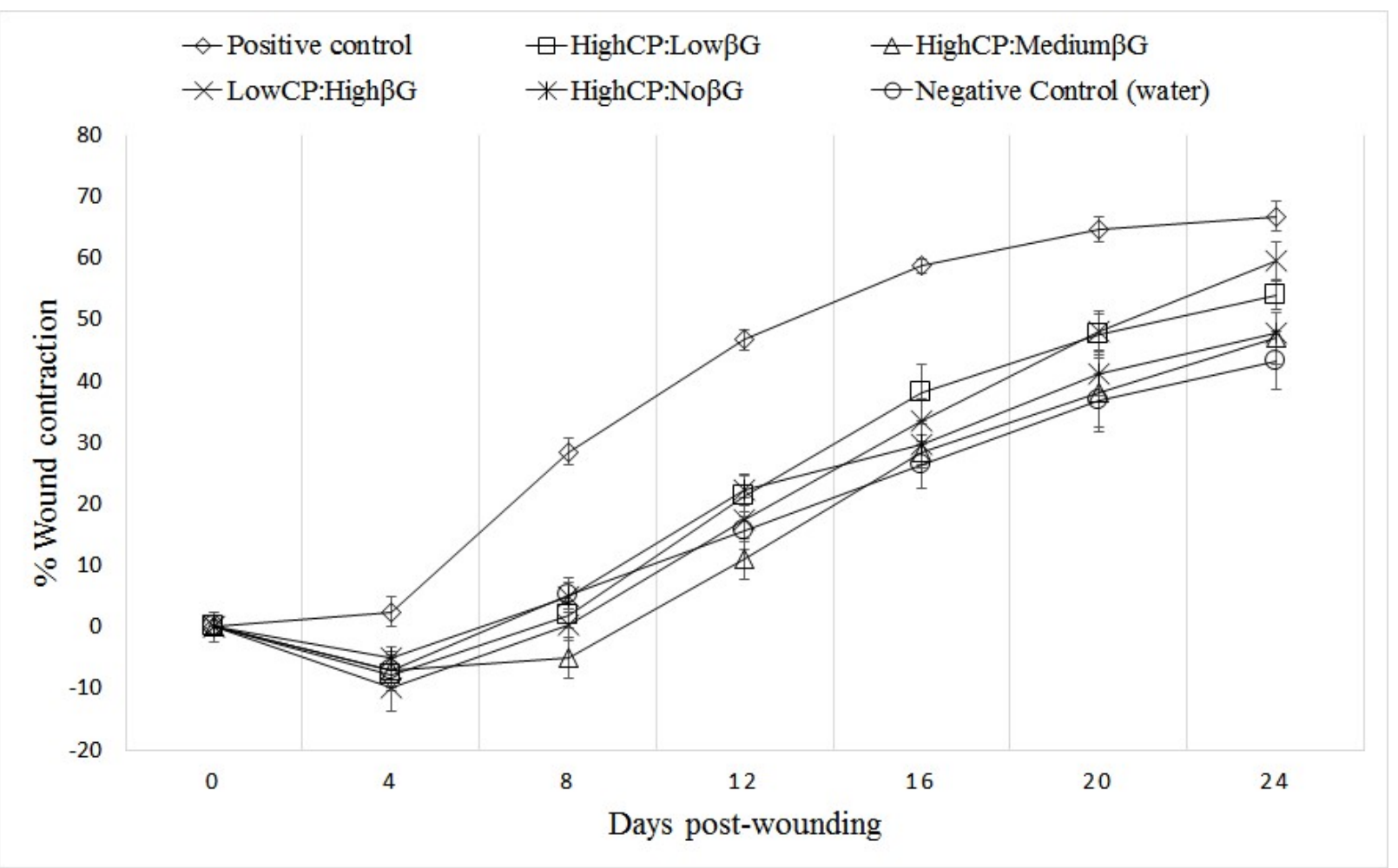

Figure 7. Wound contraction with time; \% change from mean area of original wound closure by contraction $(\% \pm \operatorname{sem})(\mathrm{n}=10)$. Positive control: $10 \mu \mathrm{g} /$ dose platelet-derived growth factor and $1 \mu \mathrm{g} /$ dose transforming growth factor alpha in $0.5 \%(\mathrm{w} / \mathrm{v})$ hydroxypropyl methylcellulose $0.5 \%$ $(\mathrm{w} / \mathrm{w})$. All formulations, except control formulations, contained $10 \%(\mathrm{w} / \mathrm{w})$ glycerol, and varying concentrations of Carbopol 971P (CP) and Soluble beta-1,3/1,6-glucan $(\beta \mathrm{G})$ :

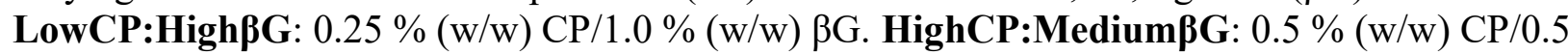

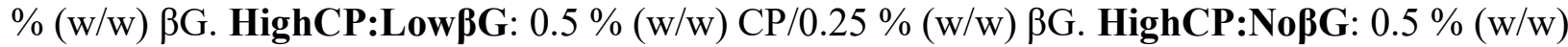
CP. 


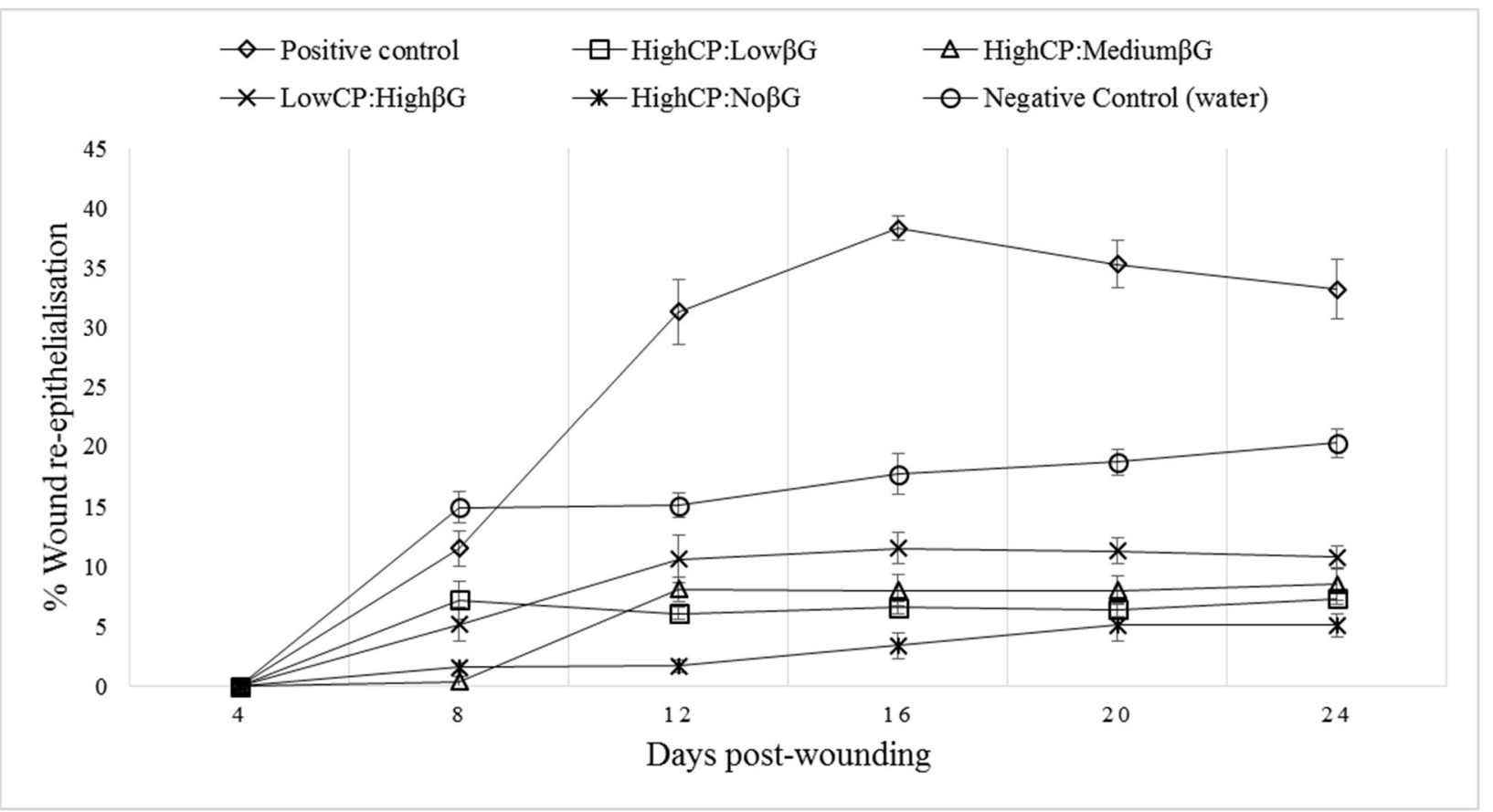

Figure 8. Re-epithelization; change in mean \% of original wound closed by re-epithelization with time (mean $\%$ area \pm sem) $(\mathrm{n}=10)$. Positive control: $10 \mu \mathrm{g} /$ dose platelet-derived growth factor and $1 \mu \mathrm{g} /$ dose transforming growth factor alpha in $0.5 \%(\mathrm{w} / \mathrm{v})$ hydroxypropyl methylcellulose $0.5 \%(\mathrm{w} / \mathrm{w})$. All other formulations, except control formulations, contained 10 $\%(\mathrm{w} / \mathrm{w})$ glycerol, and varying concentrations of Carbopol 971P (CP) and Soluble beta-1,3/1,6glucan ( $\beta \mathrm{G})$ : LowCP:High $\beta G$ : $0.25 \%(\mathrm{w} / \mathrm{w}) \mathrm{CP} / 1.0 \%(\mathrm{w} / \mathrm{w}) \beta \mathrm{G}$. HighCP:Medium $\beta$ G: $0.5 \%$ (w/w) CP/0.5 \% (w/w) $\beta$ G. HighCP:Low $\beta G: 0.5 \%$ (w/w) CP/0.25 \% (w/w) $\beta \mathrm{G}$.

HighCP:NoßG: $0.5 \%(\mathrm{w} / \mathrm{w}) \mathrm{CP}$.

\section{Conclusions}

The applied thickening/gelling agent Carbopol 971P NF showed good rheological properties considering its usage in a sprayable device destined for wound treatment, as it was acting as a fluid under higher share stress (spraying) and returning to a gel at lower share stress (e.g. in wound). However, our in vivo data in the murine $\mathrm{db} / \mathrm{db}$ wound model indicate that the Carbopol 971P NF alone does not accelerate the healing process, but does in fact have deleterious effects. Inclusion of the active ingredient, soluble beta-1,3/1,6-glucan $(\beta G)$, increased the reepithelialization and wound contraction in the $\mathrm{db} / \mathrm{db}$ mice. However, the positive effect of $\beta \mathrm{G}$ was not sufficient to counteract the adverse effect of Carbopol 971P NF in wound healing. A more suitable thickening agent should therefore be investigated, as well as a higher inclusion of $\beta \mathrm{G}$, for further development of the $\beta \mathrm{G}$-sprayable product. 


\section{Acknowledgement}

The authors would like to thank The Research Council Norway for funding under the grant number 240123/O30. We would like to acknowledge Cica Biomedical Ltd (North Yorkshire, England) and Dr. Jeff Hart, Managing Director and Dr. Andrea Bell, Principal Scientist, for support with the in vivo work.

\section{Declaration of interest}

Jostein Grip is affiliated with Biotec BetaGlucan AS, as a part of an industry sponsored PhDprogram.

\section{References}

Abdullahi, A., Amini-Nik, S., Jeschke, M.G., 2014. Animal models in burn research. Cell. Mol. Life Sci. 71, 3241-55. doi:10.1007/s00018-014-1612-5

Boateng, J.S., Matthews, K.H., Stevens, H.N.E., Eccleston, G.M., 2008. Wound healing dressings and drug delivery systems: a review. J. Pharm. Sci. doi:10.1002/jps.21210

Brar, S.K., Verma, M., Tyagi, R.D., Valéro, J.R., Surampalli, R.Y., 2007. Bacillus thuringiensis fermentation of hydrolyzed sludge - Rheology and formulation studies. Chemosphere 67, 674-683. doi:10.1016/j.chemosphere.2006.11.007

Caló, E., Khutoryanskiy, V. V., 2015. Biomedical applications of hydrogels: A review of patents and commercial products. Eur. Polym. J. 65, 252-267. doi:10.1016/j.eurpolymj.2014.11.024

Chen, L., Mirza, R., Kwon, Y., DiPietro, L.A., Koh, T.J., 2015. The murine excisional wound model: Contraction revisited. Wound Repair Regen. 23, 874-877. doi:10.1111/wrr.12338

Crittenden, J.C., Trussell, R.R., Hand, D.W., Howe, K.J., Tchobanoglous, G., 2012. Appendix C: Physical Properties of Water, in: MWH's Water Treatment. John Wiley \& Sons, Inc., 
Hoboken, NJ, USA, pp. 1861-1862. doi:10.1002/9781118131473.app3

Du, B., Lin, C., Bian, Z., Xu, B., 2015. An insight into anti-inflammatory effects of fungal betaglucans. Trends Food Sci. Technol. doi:10.1016/j.tifs.2014.09.002

Ehrlich, H.P., Hunt, T.K., 2012. Collagen Organization Critical Role in Wound Contraction. Adv. wound care 1, 3-9. doi:10.1089/wound.2011.0311

Engstad, C.S., Engstad, R.E., Olsen, J.O., Østerud, B., 2002. The effect of soluble $\beta$-1,3-glucan and lipopolysaccharide on cytokine production and coagulation activation in whole blood. Int. Immunopharmacol. 2, 1585-1597. doi:10.1016/S1567-5769(02)00134-0

Engstad, R.E., Robertsen, B., 1994. Specificity of a beta-glucan receptor on macrophages from Atlantic salmon (Salmo salar L.). Dev. Comp. Immunol. 18, 397-408. doi:10.1016/0145305X(94)90005-1

Frykberg, R.G., Banks, J., 2015. Challenges in the Treatment of Chronic Wounds. Adv. Wound Care 4, 560-582. doi:10.1089/wound.2015.0635

Greenhalgh, D.G., Sprugel, K.H., Murray, M.J., Ross, R., 1990. PDGF and FGF stimulate wound healing in the genetically diabetic mouse. Am. J. Pathol. 136, 1235-1246.

Grubbs, F.E., 1969. American Society for Quality Procedures for Detecting Outlying Observations in Samples. Source: Technometrics 11, 1-21.

Han, G., Ceilley, R., 2017. Chronic wound healing: a review of current management and treatments. Adv. Ther. 34, 599-610. doi:10.1007/s12325-017-0478-y

Hardwicke, J.T., Hart, J., Bell, A., Duncan, R., Thomas, D.W., Moseley, R., 2011. The effect of dextrin-rhEGF on the healing of full-thickness, excisional wounds in the $(\mathrm{db} / \mathrm{db})$ diabetic mouse. J. Control. Release 152, 411-417. doi:10.1016/j.jconrel.2011.03.016

Hinman, C.D., Maibach, H., 1963. Effect of air exposure and occlusion on experimental human skin wounds. Nature 200,377-378.

Home Office, 2014. Guidance on the operation of the Animals (Scientific Procedures) Act 1986, Publications GOV.UK.

Ingebrigtsen, S.G., Škalko-Basnet, N., Holsæter, A.M., 2016. Development and optimization of a 
new processing approach for manufacturing topical liposomes-in-hydrogel drug formulations by dual asymmetric centrifugation. Drug Dev. Ind. Pharm. 42, 1375-1383. doi:10.3109/03639045.2015.1135940

Jesenak, M., Urbancek, S., Majtan, J., Banovcin, P., Hercogova, J., 2015. beta-Glucan-based cream (containing pleuran isolated from pleurotus ostreatus) in supportive treatment of mild-to-moderate atopic dermatitis. J. Dermatolog. Treat. 6634, 1-4. doi:10.3109/09546634.2015.1117565

Jones, A., Vaughan, D., 2005. Hydrogel dressings in the management of a variety of wound types: a review. J. Orthop. Nurs. doi:10.1016/S1361-3111(05)80001-9

Kim, J.Y., Song, J.Y., Lee, E.J., Park, S.K., 2003. Rheological properties and microstructures of Carbopol gel network system. Colloid Polym. Sci. 281, 614-623. doi:10.1007/s00396-0020808-7

King, B., Barrett, S., Cutting, K.F., 2017. Clinical evaluation of a bioactive beta-glucan gel in the treatment of "hard-to-heal" wounds. J. Wound Care 26, 58-63. doi:10.12968/jowc.2017.26.2.58

Kumbhar, D., Wavikar, P., Vavia, P., 2013. Niosomal gel of lornoxicam for topical delivery: in vitro assessment and pharmacodynamic activity. AAPS PharmSciTech 14, 1072-82. doi:10.1208/s12249-013-9986-5

Laila, L., Febriyenti, F., Salhimi, S.M., Baie, S., 2011. Wound healing effect of Haruan (Channa striatus) spray. Int. Wound J. 8, 484-491. doi:10.1111/j.1742-481X.2011.00820.x

Lay-Flurrie, K., 2004. The properties of hydrogel dressings and their impact on wound healing. Prof. Nurse 19, 269-73.

Lubrizol, 2017. Carbopol ${ }^{\circledR}$ and Pemulen ${ }^{\mathrm{TM}}$ Products for Topical Applications - Lubrizol [WWW Document]. URL https://www.lubrizol.com/en/Life-Sciences/Products/Carbopol-PolymerProducts/Products-for-Topical-Applications (accessed 1.19.17).

Ma, J., Underhill, D.M., 2013. $\beta$-glucan signaling connects phagocytosis to autophagy. Glycobiology 23, 1047-1051. doi:10.1093/glycob/cwt046 
Novak, M., Vetvicka, V., 2008. $\beta$-Glucans, History, and the Present: Immunomodulatory Aspects and Mechanisms of Action. J. Immunotoxicol. 5, 47-57. doi:10.1080/15476910802019045

Powers, J.G., Higham, C., Broussard, K., Phillips, T.J., 2016. Wound healing and treating wounds Chronic wound care and management. J. Am. Acad. Dermatol. 74, 607-625. doi:10.1016/j.jaad.2015.08.070

Powers, J.G., Morton, L.M., Phillips, T.J., 2013. Dressings for chronic wounds. Dermatol. Ther. 26, 197-206. doi:10.1111/dth.12055

Qin, F., Sletmoen, M., Stokke, B.T., Christensen, B.E., 2013. Higher order structures of a bioactive, water-soluble $(1 \rightarrow 3)-\beta$-d-glucan derived from Saccharomyces cerevisiae. Carbohydr. Polym. 92, 1026-1032. doi:10.1016/j.carbpol.2012.10.013

Schultz, G.S., Sibbald, R.G., Falanga, V., Ayello, E.A., Dowsett, C., Harding, K., Romanelli, M., Stacey, M.C., Teot, L., Vanscheidt, W., 2003. Wound bed preparation: A systematic approach to wound management. Wound Repair Regen. doi:10.1046/j.1524-475X.11.s2.1.x

Sharma, V.K., Mazumder, B., Nautiyal, V., 2014. Rheological Characterization of Isabgol Husk, Gum Katira Hydrocolloids, and Their Blends. Int. J. Food Sci. 2014, 1-10. doi:10.1155/2014/506591

Skjæveland, I., Engstad, R., 2013. Can the activation of the body's own key cells in wound healing, wound macrophages, make a positive contribution in the treatment of chronic wounds? Sår 21 .

Soltanian, S., Stuyven, E., Cox, E., Sorgeloos, P., Bossier, P., 2009. Beta-glucans as immunostimulant in vertebrates and invertebrates. Crit. Rev. Microbiol. 35, 109-138. doi:10.1080/10408410902753746

Standard, 2002. EN 13726-1 Test methodes for primary wound dressings - Part 1: Aspects of absorbancy. Fluid Affin. Amorph. hydrogel dressings.

Stier, H., Ebbeskotte, V., Gruenwald, J., 2014. Immune-modulatory effects of dietary Yeast Beta-1,3/1,6-D-glucan. Nutr. J. 13, 38. doi:10.1186/1475-2891-13-38 
van den Berg, L.M., Zijlstra-Willems, E.M., Richters, C.D., Ulrich, M.M., Geijtenbeek, T.B., 2014. Dectin-1 activation induces proliferation and migration of human keratinocytes enhancing wound re-epithelialization. Cell Immunol. 289, 49-54.

Winter, G.D., 1962. Formation of the scab and the rate of epithelization of superficial wounds in the skin of the young domestic pig. Nature 193, 293-294.

Wong, V.W., Sorkin, M., Glotzbach, J.P., Longaker, M.T., Gurtner, G.C., 2011. Surgical approaches to create murine models of human wound healing. J. Biomed. Biotechnol. 2011, 1-8. doi:10.1155/2011/969618

Zykova, S.N., Balandina, K.A., Vorokhobina, N. V, Kuznetsova, A. V, Engstad, R., Zykova, T.A., 2014. Macrophage stimulating agent soluble yeast beta-1,3/1,6-glucan as a topical treatment of diabetic foot and leg ulcers: A randomized, double blind, placebo-controlled phase II study. J. Diabetes Investig. 5, 392-399. doi:10.1111/jdi.12165 


\section{Supplementary data}

\section{Sprayable Carbopol hydrogel with soluble beta-1,3/1,6-glucan as an active ingredient for wound healing - development and in-vivo evaluation}

Jostein Grip $^{\mathrm{a}, \mathrm{b}}$, Rolf Einar Engstad ${ }^{\mathrm{a}}$, Ingrid Skjæveland ${ }^{\mathrm{a}}$, Nataša Škalko-Basnet ${ }^{\mathrm{b}}$, Ann Mari Holsæter $^{\mathrm{b}, *}$

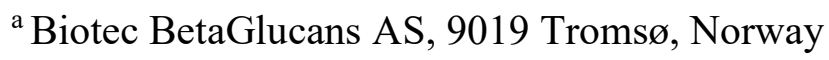

${ }^{b}$ Drug Transport and Delivery Research Group, Department of Pharmacy, Faculty of Health Sciences, University of Tromsø The Arctic University of Norway, 9037 Tromsø, Norway

\section{*Corresponding author}

Ann Mari Holsæter

E-mail address: ann-mari.holsater@uit.no

Fax: (+47) 77644900

Telephone: (+47) 77646719

Drug Transport and Delivery Research Group, Department of Pharmacy, Faculty of Health Sciences, University of Tromsø The Arctic University of Norway, 9037 Tromsø, Norway 


\section{S1. Pilot experiment: Sprayability}

Sprayability of hydrogels with $1 \%(\mathrm{w} / \mathrm{w}) \beta \mathrm{G}, 10 \%(\mathrm{w} / \mathrm{w})$ glycerol and increasing concentration of Carbopol was tested with two COMFORT ${ }^{\circledR}$ airless actuators (Ursatec Verpackung GmbH, Germany) with a spray dose of 45 and $140 \mu 1 \mathrm{pr}$ dose. The results from these experiments are presented in Table S1.

Table S1. Sprayability of hydrogels containing $1 \%(\mathrm{w} / \mathrm{w}) \beta \mathrm{G} 10 \%(\mathrm{w} / \mathrm{w})$ glycerol and increasing concentration of Carbopol.

\begin{tabular}{|c|c|c|c|}
\hline Formulation no & $\begin{array}{c}\text { Carbopol } \\
\text { concentration }(\mathbf{w} / \mathbf{w})\end{array}$ & $\mathbf{4 5} \boldsymbol{\mu l}$ actuator & $\mathbf{1 4 0} \boldsymbol{\mu l}$ actuator \\
\hline $\mathbf{1}$ & $0.25 \%$ & Sprayable & Sprayable \\
\hline $\mathbf{2}$ & $0.50 \%$ & Sprayable & Sprayable \\
\hline $\mathbf{3}$ & $0.75 \%$ & Sprayable/jet & Sprayable/jet \\
\hline $\mathbf{4}$ & $1.00 \%$ & Jet & Jet \\
\hline $\mathbf{5}$ & $1.25 \%$ & Jet & Jet \\
\hline $\mathbf{6}$ & $1.50 \%$ & Jet & Jet \\
\hline
\end{tabular}

The actuators provided a mist or spray of small droplets (aerosol) for all the applied formulations, with both the 40 and $140 \mu 1$ actuator, until a Carbopol concentration of $0.75 \%$ $(w / w)$ was reached. At this concentration, the quality of the spray was reduced, and a jet rather than an aerosol of droplets was observed. There was no noticeable difference between the two different actuators.

Of the selected formulations applied in the final study, the hydrogel with highest viscosity was the LowCP: High $\beta$ G formulation, containing $0.25 \%(\mathrm{w} / \mathrm{w})$ Carbopol and $1.0 \%(\mathrm{w} / \mathrm{w}) \beta \mathrm{G}$ and $10 \%(\mathrm{w} / \mathrm{w})$ glycerol corresponding to Formulation 1 in Table S1. Viscosity values for all formations are given in Figure 4 of the manuscript. 


\section{S2. Experimental setup for the in vivo wound healing study in mice}

A schematic presentation of the experimental setup for the in vivo studies are given in Table S2.

Table S2. Experimental setup for the wound healing experiments.

\begin{tabular}{|c|c|c|c|c|c|c|c|c|c|c|c|c|c|c|}
\hline \multirow[t]{2}{*}{$\begin{array}{l}\text { Group } \\
\text { no. }\end{array}$} & \multirow[t]{2}{*}{ Formulation applied } & \multicolumn{13}{|c|}{$\begin{array}{c}\text { Day of treatment (x) Day of (re-)anaesthetization (A) } \\
\text { Photography (P) }\end{array}$} \\
\hline & & 0 & 1 & 2 & 3 & 4 & 5 & 6 & 7 & 8 & 12 & 16 & 20 & 24 \\
\hline 1 & Positive control & $\mathrm{x}$ & $\mathrm{x}$ & $\mathrm{x}$ & $\mathrm{x}$ & $\mathrm{x}$ & $\mathrm{x}$ & $\mathrm{x}$ & & & & & & \\
\hline $2 *$ & HighCP:NoßG & $\mathrm{x}$ & & $\mathrm{x}$ & & $\mathrm{x}$ & & $\mathrm{x}$ & & & & & & \\
\hline 3* & HighCP:Low $\beta G$ & $\mathrm{x}$ & & $\mathrm{x}$ & & $\mathrm{x}$ & & $\mathrm{x}$ & & & & & & \\
\hline $4 *$ & HighCP:Medium $\beta G$ & $\mathrm{x}$ & & $\mathrm{x}$ & & $\mathrm{x}$ & & $\mathrm{x}$ & & & & & & \\
\hline 5* & LowCP:High $\beta G$ & $\mathrm{x}$ & & $\mathrm{x}$ & & $\mathrm{x}$ & & $\mathrm{x}$ & & & & & & \\
\hline 6 & Negative control & $\mathrm{x}$ & & $\mathrm{x}$ & & $\mathrm{x}$ & & $\mathrm{x}$ & & $\mathrm{x}$ & & & & \\
\hline $1-6$ & Anesthetic treatment & A & & & & $\mathrm{A}$ & & & & $\mathrm{A}$ & $\mathrm{A}$ & A & $\mathrm{A}$ & \\
\hline $1-6$ & Photography & $P$ & & & & $\mathrm{P}$ & & & & $P$ & $\mathrm{P}$ & $\mathrm{P}$ & $\mathrm{P}$ & $\mathrm{P}$ \\
\hline
\end{tabular}

*Group 2-5 were planned to be treated (x) also on day 8, but due to adverse effects in some animals, the treatment were withheld to all groups treated with Carbopol. 


\section{S3. Wound healing assessment}

Each of the 6 treatment groups in the in vivo experiment consisted of 10 diabetic mice (BKS.Cg$\mathrm{m}$ Dock $7 \mathrm{~m}+/+$ Leprdb $/ \mathrm{J}$ ) with a total of 60 animals. The response to treatment within the group varied. An example of intra-group variation can be seen when comparing photographs taken during wound healing given in Figure S1 and Figure S2. Bothe the mice in Figure S1 and Figure S2 were treated with HighCP:NoßG formulation. The buildup of slough and serious maceration and ischemia is visible in in Figure S1, especially during day 20 and 24, whereas moderate ischemia, maceration, and no slough buildup can be seen in Figure S2. In the LowCP:High $\beta G$ treated group the animals were less prone to maceration, ischemia and slough buildup (Figure S3), and they had in average a lower open wound area.
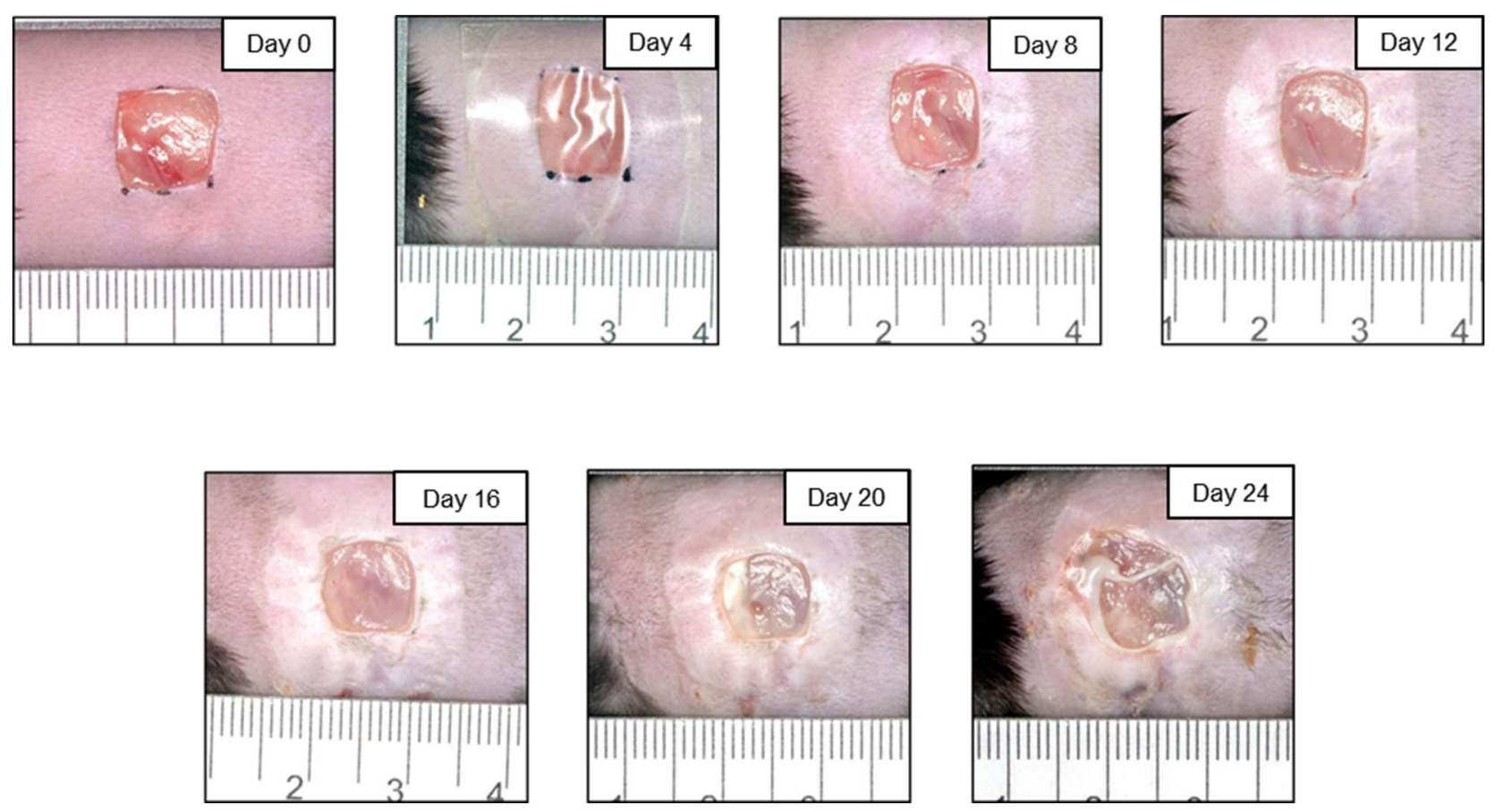

Figure S1: Photographs of a poorly healing wound treated with HighCP:NoßG. 

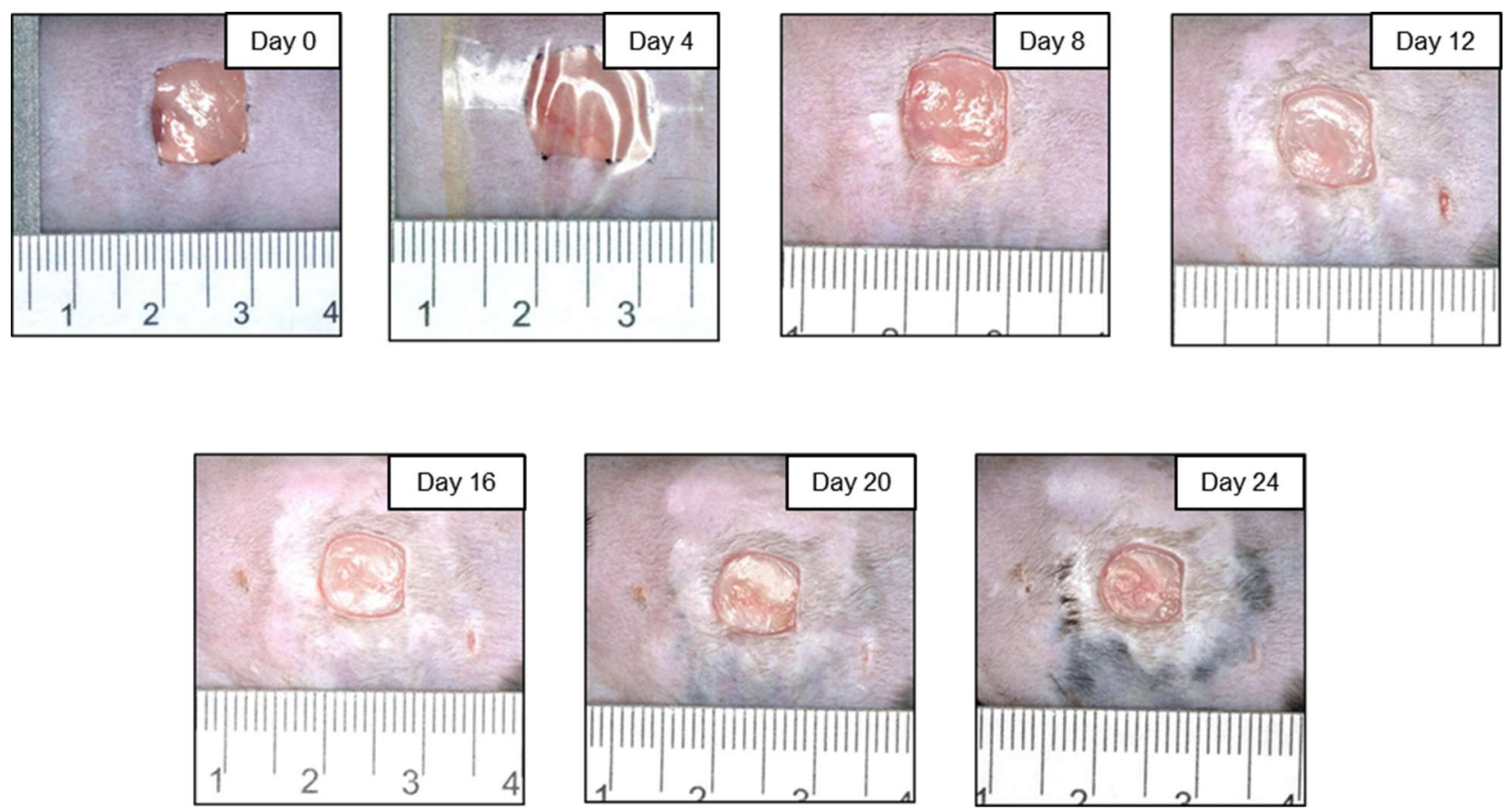

Figure S2: Photographs of one of the successfully healing wounds treated with HighCP:NoßG.
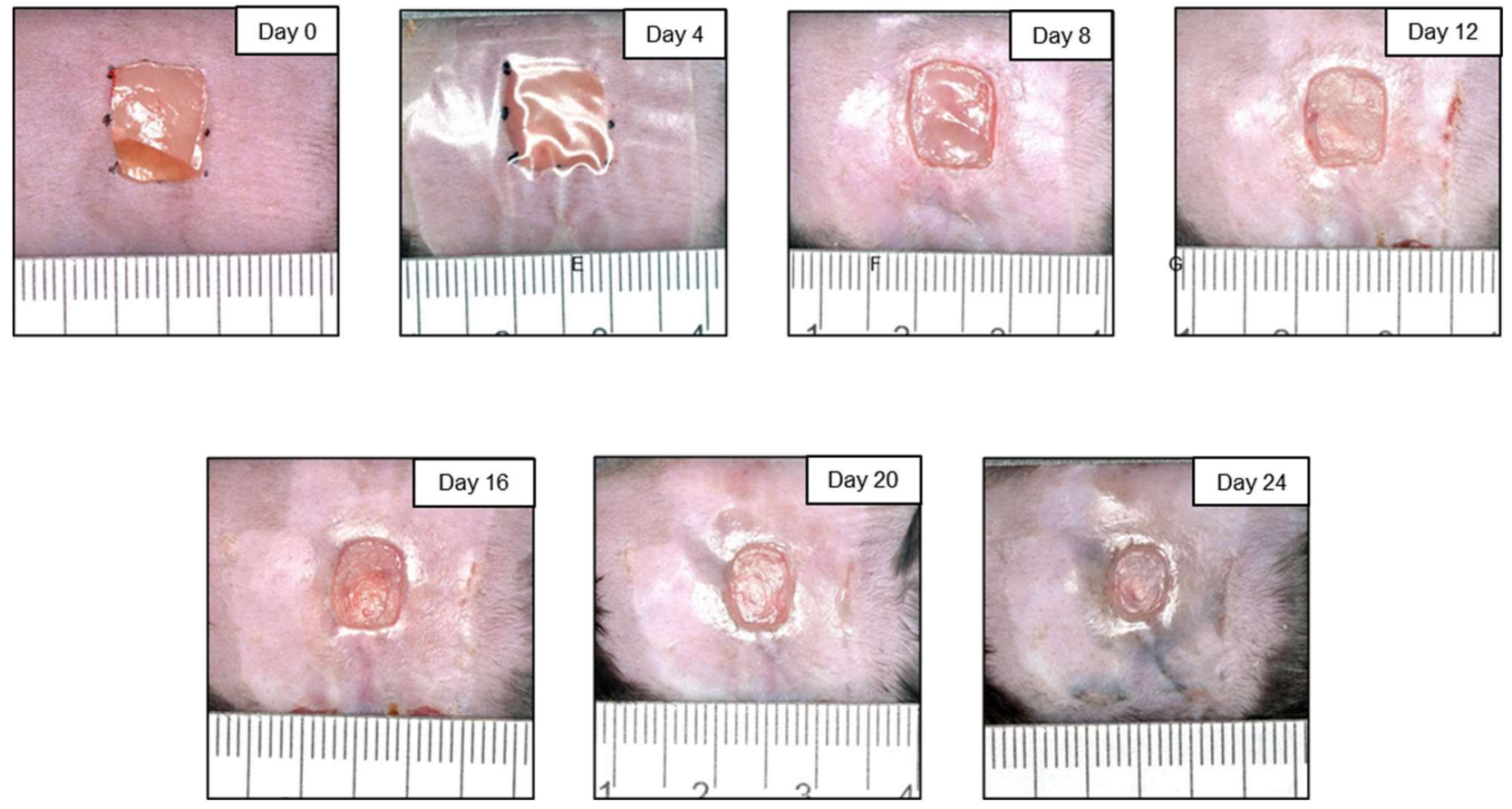

Figure S3: Photographes of a wound treated with LowCP:High $\beta$ G. 


\section{S4. Animal euthanized made do to animal welfare reasons}

Seven out of the 60 animals applied in this in vivo wound healing study were euthanized prior to the study completion due to welfare issues (Table S3). In 5 of 6 cases, the mouse was euthanized because it became evident that the wound would not heal, and the reason for euthanization was defined "related to the treatment". This included secondary wounds appearing due to selfmutilation or ischemia and maceration, primary wound enlargement with possible infections and with wound margins erythematous, ischemic and macerated. The mouse that had to be euthanized in Group no 2 had an abscess in the mouth, and this was not defined "unrelated to treatment".

Table S3. Number of animals euthanized at given time points (day) in the study

\begin{tabular}{|c|c|c|c|c|c|c|c|c|c|c|c|c|c|c|}
\hline Group & Formulation applied & \multicolumn{13}{|c|}{ Euthanasia (E) day } \\
\hline & & 0 & 1 & 2 & 3 & 4 & 5 & 6 & 8 & 10 & 12 & 16 & 20 & 24 \\
\hline 1 & Positive control & & & & & & & & & & & & & $10 \mathrm{E}$ \\
\hline 2 & HighCP:Low $\beta G$ & & & & & & & & & & & $1 \mathrm{E}^{*}$ & & $9 \mathrm{E}$ \\
\hline 3 & HighCP:Medium $\beta G$ & & & & & & & & $1 \mathrm{E}$ & $1 \mathrm{E}$ & $1 \mathrm{E}$ & & $1 \mathrm{E}$ & $6 \mathrm{E}$ \\
\hline 4 & LowCP:High $\beta G$ & & & & & & & & & & & & & $10 \mathrm{E}$ \\
\hline 5 & HighCP:NoßG & & & & & & & & & & & & $1 \mathrm{E}$ & $9 \mathrm{E}$ \\
\hline 6 & Negative control & & & & & & & & & & & & $1 \mathrm{E}^{*}$ & $9 \mathrm{E}$ \\
\hline
\end{tabular}

*Reason unrelated to treatment 